\title{
Analyzing the Variability of the Flexural Rigidity in Pre-stressed Laminated Wood Plates
}

\author{
Everaldo Pletz ${ }^{1}$, Felipe N. Arroyo ${ }^{2}$, Diego H. Almeida ${ }^{2}$, Raquel S. Cavalheiro ${ }^{3}$, \\ Julio C. Pigozzo ${ }^{4}$, André L. Christoforo ${ }^{2, *}$, Francisco A. R. Lahr ${ }^{5}$
}

\author{
${ }^{1}$ University Center Dynamics of Cataratas, Foz do Iguacu, Brazil \\ ${ }^{2}$ Centre for Innovation and Technology in Composites - CIT ${ }^{\mathrm{C}}$, Department of Civil Engineering (DECiv), Federal University of São \\ Carlos, São Carlos, Brazil \\ ${ }^{3}$ Department of Materials Engineering (SMM), Engineering School of São Carlos (EESC), São Paulo University (USP), São Carlos, Brazil \\ ${ }^{4}$ Department of Civil Engineering, Technology Center, State University of Maringá (UEM), Maringá, Brazil \\ ${ }^{5}$ Department of Structural Engineering, São Paulo University (EESC/USP), São Carlos, Brazil
}

\begin{abstract}
Although geometrical data describing structures are generally represented by their nominal values, practice has revealed that this is not the more appropriate for prestressed laminated wood plates, once the lamellae present significant size variability. The importance of this variability increases when it affects the height of plate cross sections, they also affect their moments of inertia which depends on the value of the height raised to the third power. Preliminary studies showed standard deviations of almost $10 \%$. As far as stress-laminated plates are regarded, the variability of dimensions along the length of the length of the pieces introduces a new source of variability for the cross section moment of inertia. The obtained surfaces aren't completely flat, presenting variability due the size variability along the length of the pieces. Consequently, the moment of inertia of the cross section of a stress-laminated plate is not obtained by summing up the individual moment of inertia of each piece. On the other hand, modulus of elasticity also presents a strong variability not only among the height of pieces, but also along their length. Preliminary experiments reveal a standard deviation of $23 \%$ for plates from Pinus taeda. The variability of moment of inertia of pieces and of the plate itself was determined, as well as the variability of the modulus of elasticity. The results show that rigidity just can be estimated probabilistically; that softwoods are suited for system of high redundancy; that the calculation of deformations and stress distribution along the structures are dependent on this variability and thus the referred calculations are nothing more than estimations with a certain level of confidence to be established according to the control procedures adopted; and finally that further research must be developed on probabilistic numerical factors to be incorporated to the calculation expressions of rigidity of the cross section of stress-laminated plates.
\end{abstract}

Keywords Timber, Stress Laminated Plate, Flexural Rigidity

\section{Introduction}

According to Ritter (1992) [1] prestressed laminated plates appeared in the late 1970's in Canada and gained a significant boost with the participation of USA in the technological development process from the 1980's. The prestressed-plate has as a basic arrangement solid timber layers or glued laminated with rectangular, juxtaposed and integrally through pre-stressing cross sections, supported on two opposite edges corresponding to the ends of the pieces [2] (Fig. 1).

Usually wood lamellae present commercial dimensions in the order of 10 meters with height of the cross section

* Corresponding author:

alchristoforo@gmail.com (André L. Christoforo)

Published online at http://journal.sapub.org/ijme

Copyright (C) 2017 Scientific \& Academic Publishing. All Rights Reserved ranging around " $L " / 25$, depending on the kind of bridge and width of the plate, being $L$ the plate's span. The stress system is usually constituted of high resistance hot laminated steel, from Dywidag (ST85/105 or ST105/125) with $15-32 \mathrm{~mm}$ diameter.

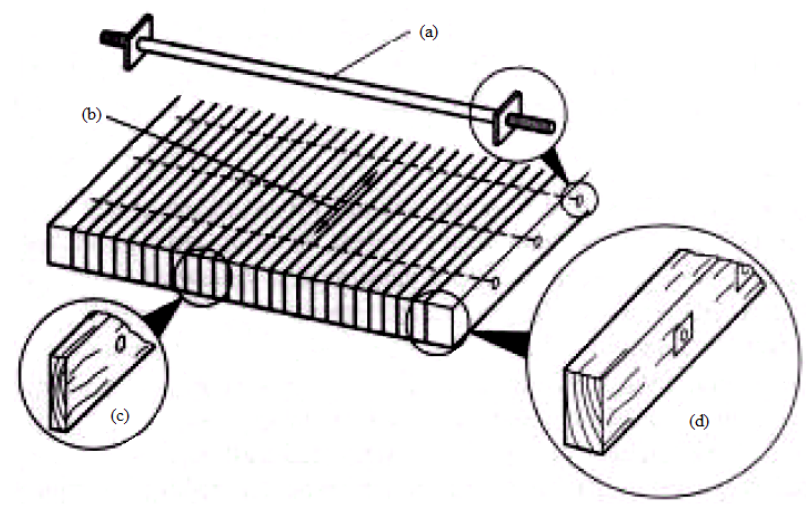

Figure 1. Pre-stressed plate 
The knowledge of the moment of inertia and elasticity modulus is essential in planning a plate [3]. In the particular case of wood laminated plates, characterized by the variability of the geometrical and physical characteristics of the material it is imperative studying its effects on those quantities.

Tests was presented confirm the suggestion from practice that the effective moment of inertia is higher than that calculated using nominal dimensions and that such variability is dependent on the adopted classification process. For the modulus of elasticity was observed a much higher variability in such parameter regarding the moment of inertia, which became lower as the classification process is more rigorous. This work aims outlining the problem stated above as well as performing a preliminary evaluation of its extension.

\section{Calculating the Moment of Inertia}

\subsection{Batch of Pinus taeda Wood Specie}

Here 43 wood beams of Pinus taeda, previously CCA treated in autoclave, with nominal dimensions of $5 \mathrm{~cm} \times$ $20 \mathrm{~cm} \times 520 \mathrm{~cm}$, presenting high incidence of defects, especially knots, were obtained from the supplier without any classificatory process. These 47 beams were disposed parallel in order to form a plate with approximately $190 \mathrm{~cm} \mathrm{x}$ $20 \mathrm{~cm} \times 520 \mathrm{~cm}$.

Initially the dimensions of the beans were measured in three sections, that means at $1 / 4,3 / 4$ and $1 / 2$ of the length. Than the center of gravity of the set was determined, taking in account effect of initial curvature of each piece in order to determine the effective moment of inertia of each lamella component of the plate.

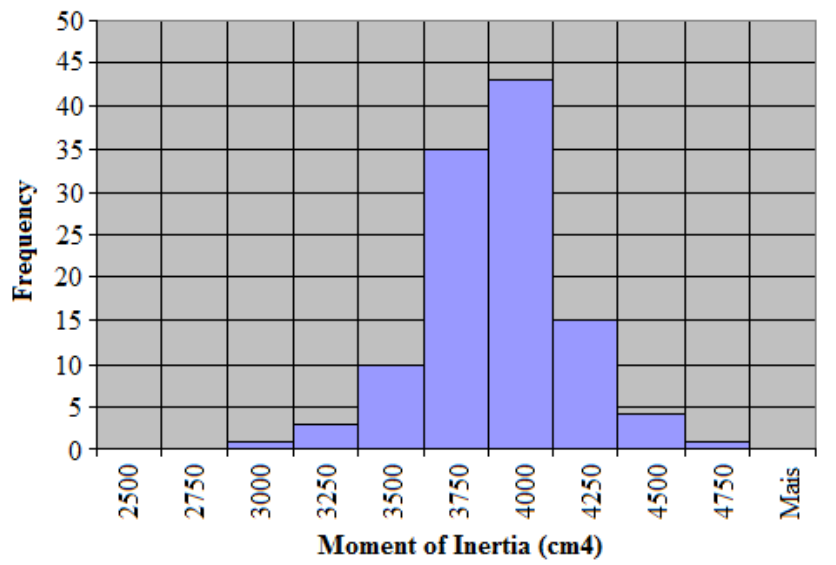

Figure 2. Moments of inertia histogram in the three sections of Pinus taeda wood specie

The average theoretical inertia was calculated using the average dimension of the sections, while for the nominal inertial the commercial dimensions were used. The actual inertia was calculated using the actual dimensions and taking in account the effect of the curvature along the length of each lamination.

It was observed that regarding the actual inertia, the average theoretical inertia presents an error of $2.96 \%$, while the nominal inertia presents an error of $-15.47 \%$. The histogram of the moments of inertia regarding the main axis of the plate (Fig 2.). The normality tests for the square roots of the moments of inertia of the sections studied presented a correlation coefficient $\mathrm{R}=0.9879$. This allows calculating the value for the characteristic moment using Eq 1.

$$
I_{k}=I_{a v}-1.645 D_{\text {esvpad }}
$$

Where: $I_{k}=3468.73 \mathrm{~cm}^{4}$, once $I_{a y}=3935.35 \mathrm{~cm}^{4}$; Desvpad $=$ standard deviation.

\section{Determining the Lamellae Modulus of Elasticity (MOE)}

Were determined lamellae modulus of elasticity for two wood species: Pinus taeda and Corymbia citriodora.

\subsection{Batch of Pinus taeda Wood Specie}

Batch Pinus taeda wood specie with laminations with dimensions $5 \mathrm{~cm} \times 20 \mathrm{~cm} \times 520 \mathrm{~cm}$ treated against biological demand using CCA in autoclave was assayed for flexion, being the elasticity modulus determined twice for each specimen. In the first determination the specimen is placed in a lying position and in the second one in a standing position (Fig 3). MOE presented the following average values: 4117 $\mathrm{MPa}$ (lying down) and $5748 \mathrm{MPa}$ (standing) with standard deviations of $26.61 \%$ e $26.97 \%$, respectively. Data reported by Okimoto (2000) [4] presented standard deviation of $32.6 \%$ for Pinus taeda timber while Pigozzo et al. (2000) [5] claimed $22.89 \%$ in their reference number.

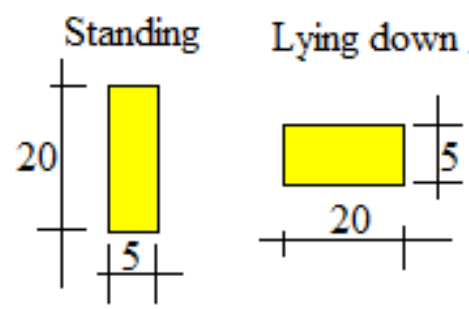

Figure 3. Standing and lying down position (units in $\mathrm{cm}$ )

Both authors perform a visual classification of the tested specimens. The normality tests revealed a variation coefficient $\mathrm{R}=0.9847$ and 0.9802 respectively. The histograms of the elasticity modulus obtained for the two positions are presented in Figure 4. Fig. 5 representing the range of the elasticity modulus along the cross section are presented in Figure 5. 


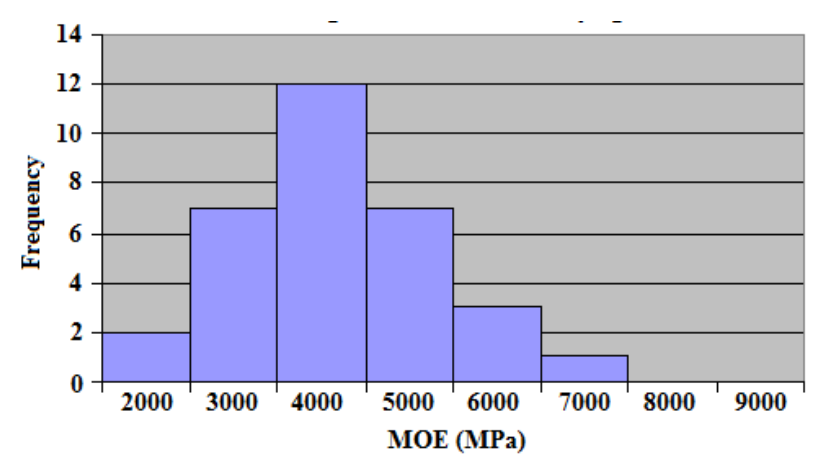

(a)

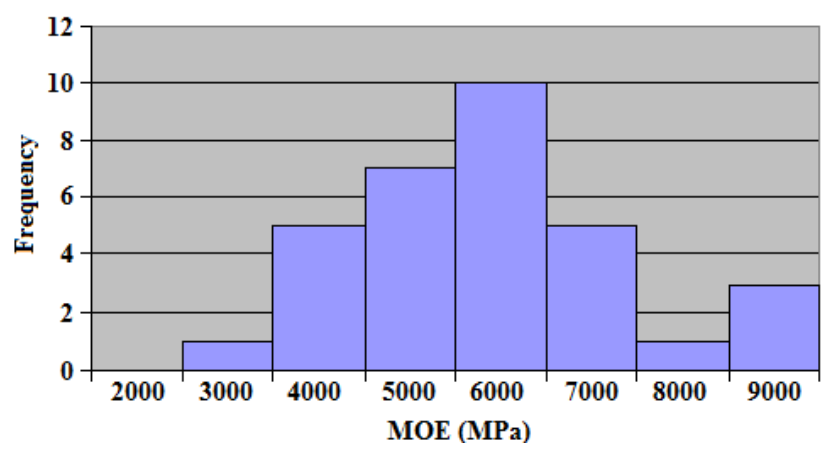

(b)

Figure 4. MOE histogram for Pinus taeda wood specie in both positions: (a) lying down and (b) standing

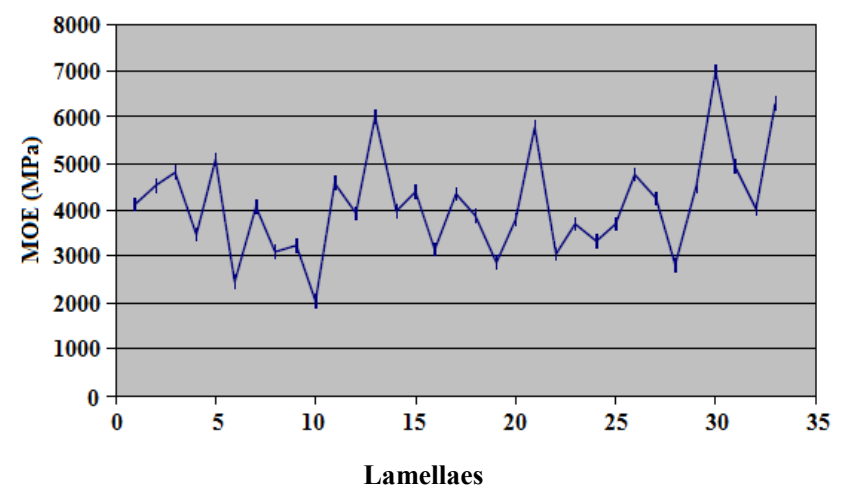

(a)

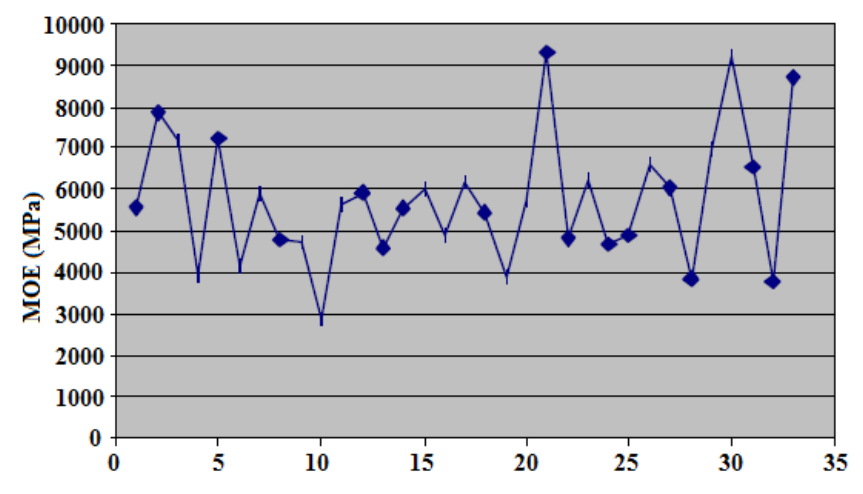

Lamellaes

(b)

Figure 5. MOE for Pinus taeda in both positions: (a) lying down and (b) standing

\subsection{Batch of Corymbia citriodora Wood Specie}

After visual selection 84 pieces from Corimbia citriodora measuring 1 x 5 x $192 \mathrm{~cm}$ were tested by Okimoto (1997) [6] regarding flexion in a position in which strength was parallel to the highest inertia. The elasticity modulus presented an average value of $2064 \mathrm{MPa}$ and a standard deviation of $14.09 \%$ (Fig 6).

Analyzing the frequency of distribution of the elasticity modulus values it was possible to confirm their normality with a correlation coefficient $R=0.9893$. Fig. 7 presents the range of the modulus of elasticity values along the cross section of the plate, demonstrating how this feature depends on the spatial position.

\subsection{Determination of the Stiffness (EI)}

In order to evaluate the variability in the stiffness of a set of laminations composing a plate the values of the elasticity modulus of Pinus taeda essayed standing was attributed to the set as their variability of the moment of inertia. Although the values of the moment of inertia were those from a different lot regarding the modulus of elasticity, one can consider that this fact do not affects significantly the evaluation of the variability of the product of these two variables. The error estimated during the calculation of the product $\mathrm{E} x \mathrm{I}$ is of $53.33 \%$ when considering the average values of $\mathrm{E}$ and $\mathrm{I}$, and such error is increased if one uses the nominal dimensions. Interesting results were found by adopting the average dimensions in the calculation of the moment of inertia.

The measurements of the beans from Pinus Taeda timber as studied here and the calculations of the moments of inertia according the several acceptable modeling possibilities demonstrated that errors in the level of $15 \%$ can be achieved, when considering the nominal values of their dimensions and mainly considering that the longitudinal axis is straight.

These same measurements and calculations demonstrated that the determination of the moment of inertia presents a relatively small error of $3 \%$ when the average dimensions of the pieces is considered.

The frequency for the values of the moment of inertia of the pieces followed a normal distribution, whit a relatively low standard deviation in the level of $7 \%$.

Flexure tests of the pieces of Pinus taeda wood specie without classification demonstrated the significant influence of the knots in the value of the elasticity modulus.

Frequency values of modulus of elasticity in Pinus taeda lamellae followed normal distribution, also with a relatively low standard deviation $(25 \%)$, however higher than that observed for the moment of inertia.

Tests with Corymbia citriodora lamellae led to similar results to those observed for Pinus taeda samples. However a lower standard deviation (15\%) was observed, probably due to classification procedure adopted.

All tests performed has demonstrated that the properties evaluated vary along the length of the lamellae as well as among lamellae. 


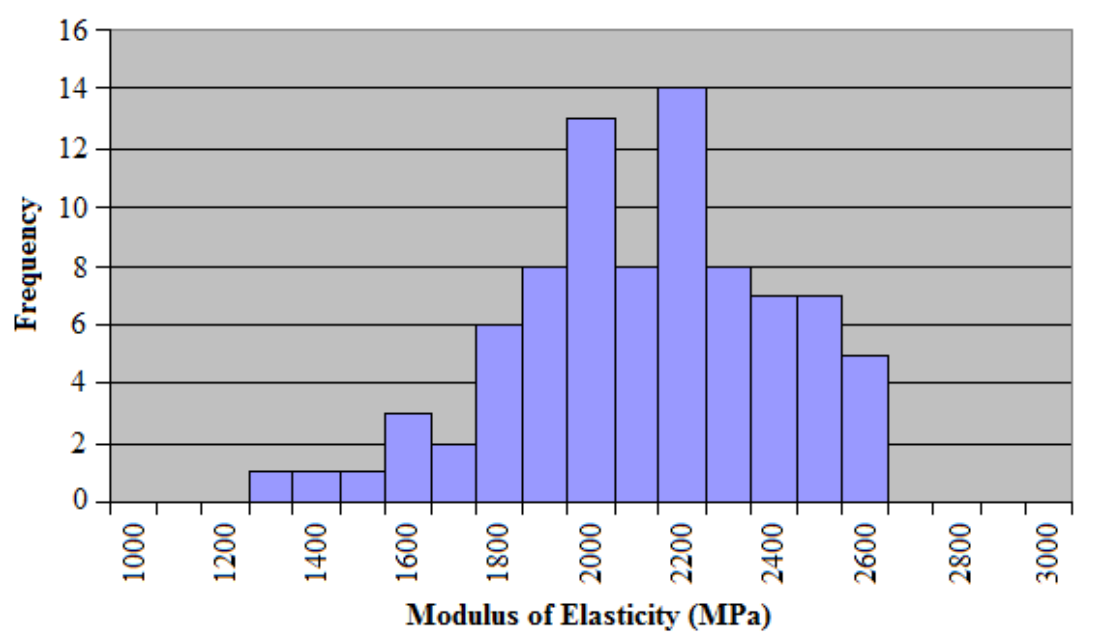

Figure 6. MOE histogram for Corymbia citriodora wood specie

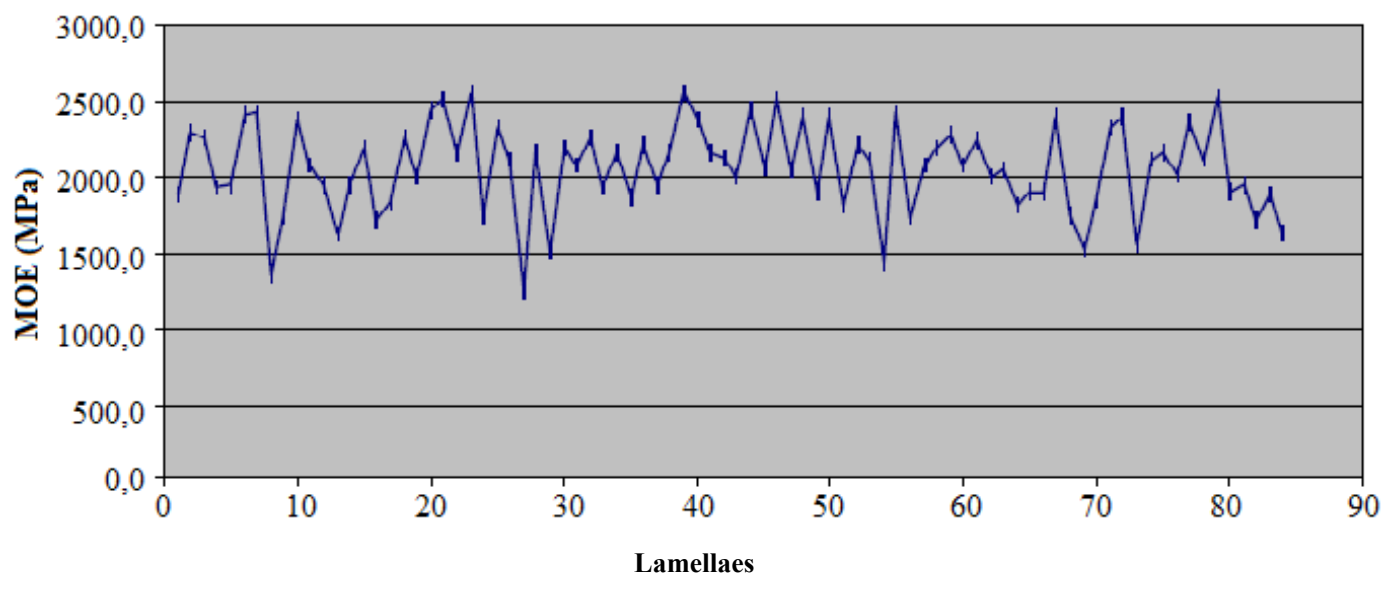

Figure 7. MOE for each Corymbia citriodora lamellae

Static bending tests of Pinus taeda lamellae, carried out to determine their geometric properties in order to obtain stiffness (EI), demonstrated that the most practical way to do it is by considering the average values of elasticity modulus and of the moment of inertia.

Once the frequency of distribution of the $\mathrm{E} x \mathrm{I}$ values presented a slight asymmetry, may be that a Weibull distribution could be more adequate in this case.

\section{Conclusions}

From the results presented here it can be concluded that:

- Plates of prestressed laminated timber present EI heterogeneity distributed along its surface. This is the cause of non-homogeneity on their structural behavior along surfaces, explaining why symmetrical actions can provoke asymmetrical responses in this kind of plates, regarding displacements or internal forces.

- The heterogeneity observed for the elasticity modulus of elasticity is quite higher than that for the moment of inertia.

- Initial curvatures of the timber lamellae increase the moment of inertia of the plate. However this positive feature of the initial curvature can become negative in the case if some members are submitted to compression parallel to grain, with increasing eccentricity of the solicitation.

- To check structures regarding their ultimate limit states requires consideration of their characteristic moment of inertia, but when considering the serviceability limit states the average value must be considered.

- It is imperative testing structural pieces in order to evaluate their mechanical properties, mainly when using timber came from tress with quick growing.

- The presence of knots is as noxious as smaller is the cross section parallel to the solicitation axis. Special attention must be paid to structures subject to compression.

- It is important to perform a timber pieces selection both from the geometrical regard as the mechanical one.

It is necessary developing more studies to relate the classification process of the timber pieces with the procedure for calculating the moment of inertia, taking in account the discrepancy between the nominal and effective dimensions of each piece. 


\section{ACKNOWLEDGMENTS}

Authors thank to Wood and Timber Structures Laboratory (LaMEM), Structural Engineering Department (SET), São Carlos Engineering School (EESC), São Paulo University, by the materials and resources used in this research.

\section{REFERENCES}

[1] Ritter, M. A. Timber bridges-design: construction, inspections and maintenance. Madison: FPL. 1992.

[2] Pigozzo, J. C.; Arroyo, F. N.; Cavalheiro, R. S.; Christoforo, A. L.; Pletz, E.; Lahr, F. A. R. Aspects of mechanical stress grading for structural timber. International Journal of Materials Engineering, v. 6, p. 119-125, 2016.
[3] Pletz, E. Passarela estaiada de madeira laminada protendida com módulos curvos. 2001, 129 p. Monografia (Exame de Qualificação para Doutorado), Departamento de Engenharia de Estruturas, Universidade de São Paulo, São Carlos, 2001.

[4] Okimoto, F. S. Análise da perda de protensão em pontes protendidas de madeira. 2000, $111 \mathrm{p}$. Monografia (Exame de Qualificação para Doutorado), Departamento de Engenharia de Estruturas, Universidade de São Paulo, São Carlos, 2000.

[5] Pigozzo, J.; Pletz, E.; Lahr, F. A. R. Aspectos da classificação mecânica de peças estruturais de madeira. In: Encontro Brasileiro em Madeiras e Estruturas de Madeira. VII, São Carlos: Ibramem, 2000.

[6] Okimoto, F. S. Pontes protendidas de madeira: parâmetros de projeto. 1997, 111p. Dissertação (Mestrado em Engenharia de Estruturas), Universidade de São Paulo, Departamento de Engenharia de Estruturas, São Carlos, 2000. 